\title{
Alveolar Hypoxia-Induced Pulmonary Inflammation: From Local Initiation to Secondary Promotion by Activated Systemic Inflammation
}

\author{
Ting Chen ${ }^{\mathrm{a}-\mathrm{d}}$ Chengzhong Yang ${ }^{\mathrm{a}-\mathrm{c}}$ Manman $\mathrm{Li}^{\mathrm{a}-\mathrm{d}}$ Xiaoling Tan ${ }^{\mathrm{a}-\mathrm{c}}$ \\ a Department of High Altitude Physiology and Biology, College of High Altitude Medicine, and b Key Laboratory of \\ High Altitude Medicine, Third Military Medical University, Ministry of Education, `Key Laboratory of High Altitude \\ Medicine, People's Liberation Army, and ' Laboratory of Stem Cell and Tissue Engineering, Chongqing Medical \\ University, Chongqing, China
}

\section{Key Words}

Initiation · Preservation - Pulmonary inflammation .

Hypoxic pulmonary hypertension - Alveolar hypoxia

\begin{abstract}
Pulmonary hypertension $(\mathrm{PH})$ is a pathological condition with high mortality and morbidity. Hypoxic $\mathrm{PH}(\mathrm{HPH})$ is a common form of $\mathrm{PH}$ occurring mainly due to lung disease and/or hypoxia. Most causes of HPH are associated with persistent or intermittent alveolar hypoxia, including exposure to high altitude and chronic obstructive respiratory disease. Recent evidence suggests that inflammation is a critical step for HPH initiation and development. A detailed understanding of the initiation and progression of pulmonary inflammation would help in exploring potential clinical treatments for $\mathrm{HPH}$. In this review, the mechanism for alveolar hypoxia-induced local lung inflammation and its progression are discussed as follows: (1) low alveolar $\mathrm{PO}_{2}$ levels activate resident lung cells, mainly the alveolar macrophages, which initiate pulmonary inflammation; (2) systemic inflammation is induced by alveolar hypoxia through alveolar macrophage activation; (3) monocytes are recruited into the pulmonary circulation by alveolar hypoxia-induced macrophage activation, which then contributes to the progression of pulmo-
\end{abstract}

nary inflammation during the chronic phase of alveolar hypoxia, and (4) alveolar hypoxia-induced systemic inflammation contributes to the development of $\mathrm{HPH}$. We hypothesize that a combination of alveolar hypoxia-induced local lung inflammation and the initiation of systemic inflammation ("second hit") is essential for HPH progression.

(c) 2016 S. Karger AG, Base

\section{Introduction}

Pulmonary hypertension $(\mathrm{PH})$ is defined as abnormally high blood pressure in the pulmonary arteries, which increases the workload of the right side of the heart and leads to cardiac hypertrophy over time; eventually, heart failure may result. There are 5 categories of $\mathrm{PH}$ classified by the World Health Organization (WHO) [1]. Group III consists of hypoxic $\mathrm{PH}(\mathrm{HPH})$ due to lung diseases and/ or hypoxia, including obstructive airway diseases, pulmonary edema due to heart failure and acute lung injury, or physiological conditions, such as exposure to high altitude. Many of these pathological conditions are associated with persistent or intermittent alveolar hypoxia that occurs when alveolar epithelial cells (AEPCs) are exposed to lower oxygen tensions $[2,3]$.

\section{KARGER}

E-Mail karger@karger.com

www.karger.com/jvr (c) 2016 S. Karger AG, Basel

$1018-1172 / 16 / 0536-0317 \$ 39.50 / 0$
Dr. Xiaoling Tan

Department of High Altitude Physiology and Biology

College of High Altitude Medicine, Third Military Medical University

Gaotanyan Street 30, Shapingba District, Chongqing 400038 (China)

E-Mail tanxl0511@163.com 
The basic mechanism for HPH is linked to sustained vascular constriction and remodeling resulting from a series of responses by pulmonary vascular cells to hypoxia. Recent reviews have addressed the potential cellular and molecular mechanisms that contribute to these processes [4-9]. In addition, accumulating evidence has shown that acute and chronic exposure of animals to even moderate alveolar hypoxia results in increased expression of lung inflammatory cytokines, chemokines, and adhesion molecules; it also leads to the accumulation of bloodstream monocytes within the lung interstitium and lung blood vessels [10-23].

Interestingly, with the exception of the pulmonary vascular system, no blood-born cell infiltration has been detected at other tissue vessels during the acute phase of alveolar hypoxia [24, 25]. Moreover, cell migration during pulmonary circulation is not initiated by low systemic $\mathrm{PO}_{2}$ levels, but by the activation of alveolar macrophages (AMOs) [26-28]. HPH is usually characterized by mild to moderate pulmonary vascular remodeling that is thought to be reversible when oxygen deficiency is attenuated. However, there are severe $\mathrm{PH}$ cases in which pulmonary vascular remodeling is irreversible $[1,29]$. The remarkable differences between the 2 situations are with respect to cell infiltration and cytokine secretion patterns in the pulmonary artery, especially in the adventitia. This suggests that inflammatory responses during pulmonary circulation are critical for HPH development. However, it is still unclear how alveolar hypoxia initiates and promotes the recruitment and arrest of cells from the bloodstream and into the pulmonary circulation.

The purpose of this review is to summarize published evidence that supports the following: (1) alveolar hypoxia evokes specific pulmonary responses; (2) low alveolar $\mathrm{PO}_{2}$ levels activate resident lung cells, mainly AMOs, which then initiate pulmonary inflammation; (3) activation of AMOs results in alveolar hypoxia-induced systemic inflammation, also known as a systemic "second hit", and (4) activation of AMOs also triggers the recruitment of circulatory monocytes to the pulmonary vasculature, which contributes to the progression of pulmonary inflammation during the chronic phase of alveolar hypoxia.

\section{Alveolar Hypoxia Evokes Specific Pulmonary Responses}

The lungs display specific responses to hypoxia compared to other systemic organs. First, the normal alveolar $\mathrm{PO}_{2}$ level $(110 \mathrm{~mm} \mathrm{Hg})$ is significantly higher compared to that of other internal organs, in which oxygen tension ranges from 3 to $20 \mathrm{~mm} \mathrm{Hg}$ for healthy patients [30]. Second, hypoxic responses are observed in the lungs at $\mathrm{PO}_{2}$ values $(50-60 \mathrm{~mm} \mathrm{Hg}$ ) that are higher than those of other organs, even under conditions of normal oxygenation [31]. Third, an acute onset of hypoxia leads to pulmonary arterial constriction, while it triggers vasodilatation in other organs [32]. Fourth, hypoxia alters the expression of specific genes in the lungs, which are not activated in other organs. RELM- $\alpha$ (resistin-like molecule- $\alpha$ ), gremlin1, and CXCR7 (CXC chemokine receptor type 7) have been shown to be associated with HPH progression [3339].

Recently, many studies have demonstrated that alveolar hypoxia results in an accumulation of monocytes/ macrophages at the pulmonary vasculature. In a study by Wood et al. [40], alveolar hypoxia was produced in rats by having the animals breathe $10 \% \mathrm{O}_{2}$, which induces increased leukocyte-endothelial interactions within minutes, followed by leukocyte emigration to the perivascular space within 2-4 h. A recent study by Burke et al. [25] showed an abundance of mononuclear cells at the pulmonary artery adventitia of infant rats and neonatal calves exposed to chronic hypoxic conditions. A time course (24 h to 4 weeks) analysis shows that monocytes appear early in the pulmonary artery adventitia and accumulate over the period of hypoxia exposure. Interestingly, the hypoxia-induced accumulation of monocytes/macrophages appears to be specific for the pulmonary artery, since no such recruitment is observed in systemic circulation, i.e., for the aorta. Nevertheless, a few T cells, but no B cells or neutrophils, can be observed at the pulmonary vessel wall at various time points. A study by Minamino et al. [41] demonstrates that mice exposed to $8-10 \%$ oxygen for $48 \mathrm{~h}$ to 5 days exhibit a marked induction of proinflammatory cytokines and chemokines, including monocyte chemoattractant protein (MCP)-1, macrophage inflammatory protein (MIP)-2, interleukin (IL)-1, IL-6, as well as increased numbers of macrophages and neutrophils, followed by pulmonary structural remodeling.

The effects of acute alveolar hypoxia on leukocyte recruitment and cytokine production have also been studied in humans. Patients with high-altitude pulmonary edema have a higher absolute number of cells in bronchoalveolar lavage fluid, especially neutrophils and macrophages, compared to healthy individuals $[42,43]$. In addition, increased levels of TNF- $\alpha$, IL-1, IL- 6 , and IL-8 have been reported, which quickly subside to normal levels upon recovery [44]. Ex vivo studies of human lung tissue isolated from patients with severe chronic pulmonary 
arterial hypertension have revealed inflammatory cell infiltrates (macrophages and lymphocytes) in plexiform lesions, as well as increased expression of the chemokines RANTES and fractalkine [45-49].

Taken together, alveolar hypoxia induces leukocyte infiltration into the lungs and walls of pulmonary arteries, which are involved in vasoconstriction and vascular remodeling $[4,22]$. Leukocytic invasion into other ischemic or hypoxic tissues has also been reported [50-57]. However, the triggers for these specific inflammatory responses of the pulmonary vascular system are still unidentified [58-61]. Recent progress on this issue will be discussed further.

\section{Low Alveolar $\mathrm{PO}_{2}$ Levels Activate Resident Lung Cells, Which Then Initiate Pulmonary Inflammation}

Among the resident lung cells, AMOs and dendritic cells (DCs) are located in close proximity to the epithelial surface of the respiratory system and the capillaries where they can rapidly sense changes in oxygen tension. Besides these cells, vascular endothelial cells also play a key role in hypoxia-induced inflammation by secreting proinflammatory factors and mediating leukocyte activation. The immediate responses of these cells to low alveolar hypoxia result in increased secretion of inflammatory factors and cell migration in the pulmonary alveolus and pulmonary interstitium; these responses create an inflammatory microenvironment in the pulmonary circulation. The following experimental evidence supports the idea that resident lung cells initiate alveolar hypoxia-induced pulmonary inflammation.

\section{Alveolar Macrophages}

An AMO (or dust cell) is a type of macrophage found in the pulmonary alveolus, near the AEPC, but separated from the wall. The activity of AMOs is relatively high, since they are located at one of the major boundaries between the body and the outside world. AMOs are phagocytes that play a critical role in homeostasis, host defense, responses to foreign substances, and tissue remodeling. Activated AMOs release numerous secretory products and interact with other cells and molecules through the expression of several surface receptors. AMOs are also involved in the phagocytosis of apoptotic and necrotic cells that have undergone cell-death.

In vitro models have shown that reductions in alveolar $\mathrm{PO}_{2}$ levels or oxygen concentration activate AMOs, which then results in the rapid release of mitogenic and angio- genic factors, including $\mathrm{H}_{2} \mathrm{O}_{2}$, MCP-1 [62-64], IL-1, and IL-6 $[17,65,66]$. In addition, AMOs secrete inflammatory factors, such as $15 \mathrm{~d}-\mathrm{PGJ}_{2}(15$-deoxy- $\Delta(12,14)$-prostaglandin- $\mathrm{J}_{2}$ ), in the bronchoalveolar lavage, which is followed by neutrophil recruitment [67]. It has also been shown that acute hypoxia induces enhanced NF- $\kappa \mathrm{B}$ activation by AMOs, which may result in the increased production and release of inflammatory cytokines such as TNF [68]. A study using an animal model showed that rats breathing $10 \% \mathrm{O}_{2}$ for periods ranging from 1 to $8 \mathrm{~h}$ exhibit increased albumin extravasation and pulmonary expression of HIF- $1 \alpha, \mathrm{NF}-\kappa \mathrm{B}$, and proinflammatory cytokines. However, these changes are attenuated by the elimination of AMOs [10, 62, 68, 69].

Although AMOs and peritoneal macrophages originate from the same progenitor in the bone marrow, the different $\mathrm{PO}_{2}$ levels in the environments in which they reside may determine their sensitivity to oxygen levels. Under normoxic conditions, AMOs are exposed to $\mathrm{PO}_{2}$ levels of approximately 100 Torr, while systemic tissue macrophages reside in environments where $\mathrm{PO}_{2}$ values range between 20 and 40 Torr. A study by Chao et al. [26] shows that lowering $\mathrm{PO}_{2}$ levels from 100 to 70 Torr induces a transitory release of $\mathrm{H}_{2} \mathrm{O}_{2}$, a reflection of an AMO respiratory burst, into the supernatant of primary AMO cultures. Furthermore, the magnitude of $\mathrm{H}_{2} \mathrm{O}_{2}$ release is inversely related to the $\mathrm{PO}_{2}$ level. In contrast, lowering $\mathrm{PO}_{2}$ levels to 5 Torr did not induce a respiratory burst in peritoneal macrophages. To put these values into perspective, intact rats breathing $10 \% \mathrm{O}_{2}$ show cremaster microvascular $\mathrm{PO}_{2}$ levels of approximately 6-8 Torr. AMOs have a high sensitivity to oxygen changes and lung location, thereby triggering pulmonary inflammation under alveolar hypoxia conditions. The discrepancies in hypoxia responses between AMOs and peritoneal macrophages highlight the different characteristics of these cell types. The different $\mathrm{PO}_{2}$ levels of the environments in which they reside may determine their metabolic patterns and perhaps explain their different responses to hypoxia [70]. However, the mechanisms underlying this distinct activity of AMOs under low oxygen levels are still unclear.

\section{Lung Dendritic Cells}

Lung DCs play a fundamental role in sensing invading pathogens and in controlling tolerogenic responses in the respiratory tract. They are distributed along the airways and throughout the pulmonary interstitium in close proximity to the overlying AEPCs. At least 3 main subsets of lung DCs have been identified in mice: conventional DC (cDC), plasmacytoid DC (pDC), and IFN-producing 
killer DC (IKDC). The cDC subset is the most prominent subset in the lungs $[71,72]$. It has been shown that hypoxia inhibits the maturation and differentiation of monocyte-derived DCs, but promotes the production of proinflammatory cytokines [73]. However, the response of lung DCs to alveolar hypoxia and their role in the initiation of pulmonary inflammation remain unclear.

\section{Alveolar Epithelial Cells}

Another resident cell that reacts to low alveolar oxygen tension is the AEPC. The mammalian pulmonary alveolar epithelium is comprised of 2 types of cells, called AEPCII and AEPCI. AEPCII can transdifferentiate into AEPCI to repair damaged epithelium after lung injury or during fetal lung development. AEPCII grown in primary culture can be observed to undergo such transitions in vitro.

AEPCs provide a rich source of chemokines and modulate inflammatory cell migration. Recent studies propose that the chemokine CCL20 (MIP-3 $\alpha$ ) may play an important role in DC recruitment. It has been shown that primary human AEPCII cells, but not human AMOs, produce CCL20. In addition, peripheral blood monocytederived $\mathrm{CD}_{1} \mathrm{a}^{+}$DCs migrate in response to conditioned media from AEPCII cells but not those from AMOs. DC migration was significantly correlated with the amount of CCL20 detected in the media but not with any other chemokine measured [74]. A study by Beck-Schimmer et al. [69] detected the expression of adhesion molecules, ICAM- 1 and VCAM-1, on AEPCs, and identified their biological function under hypoxic conditions. At 5\% oxygen levels, ICAM-1 and VCAM-1 mRNA increased by $100 \%$, peaking between 0.5 and $1 \mathrm{~h}$, and further increasing between 2 and $4 \mathrm{~h}$. Neutrophil adherence to hypoxiainduced AEPCs was enhanced by $115 \%$, and was inhibited with an anti-ICAM- 1 antibody. Adherence of AMOs to AEPCs increased by $118 \%$, and was blocked with an anti-VCAM-1 antibody. These results suggest that adhesion of leukocytes and macrophages to lung epithelial cells might play an important role in pulmonary inflammation during hypoxic conditions.

Studies have shown that the interaction of AMOs and AEPCs results in the release of proinflammatory mediators in the lungs, which may then induce a systemic inflammatory response [75-78]. However, there is no direct evidence that an AMO-epithelial cell interaction is required for the initiation of alveolar hypoxia-induced pulmonary inflammation. An acute hypoxia-reoxygenation cell model has shown that activated AMOs enhance the proinflammatory response of AEPCs. AMO-produced TNF- $\alpha$ further induces AEPCs to produce key chemo- kines that could then contribute to subsequent lung injury through neutrophil recruitment [78]. Another report suggested that interactions of AMOs with respiratory epithelium may play a key role in hyperoxia-induced lung inflammation [75]. In this study, pulmonary epithelial cells (A549) and monocyte/macrophage cells (THP-1) were cultured either singly, in contact coculture, or prevented from contact by a porous membrane, and then exposed to oxygen or room air. Neither cell line cultured alone produced detectable levels of IL- 8 under hyperoxia conditions. Contact cocultures exposed to hyperoxia produced increased levels of IL-8, while in the noncontact coculture it was attenuated [76]. These results suggest that the interaction between AMOs and AEPCs contributes to the production of mediators that induce an inflammatory response [77]. Future studies should examine how the interaction of AMOs and AEPCs, the 2 oxygen-sensing biomolecular species in the lungs, leads to the initiation and development of alveolar hypoxia-induced pulmonary inflammation.

\section{Vascular Endothelial Cells}

Vascular endothelial cell activation is an important response to hypoxia in a variety of vascular beds. Vascular endothelial cells secrete a multitude of proinflammatory mediators and express adhesion molecules that promote leukocyte recruitment into hypoxic or injured areas. It has been shown that massive leukocytes that accumulate at the pulmonary artery originate from the bloodstream. However, it is still unknown whether endothelial cells initiate lung inflammation alone.

Pulmonary arterial endothelial cell responses to lung ischemia-reperfusion injury are not robust enough to drive the development of lung injury independently. The activation of AMOs enhances the proinflammatory response of endothelial cells to hypoxia [79]. A study by McCourtie et al. [79] provided evidence that the secretory products of AMOs amplify the response of cultured endothelial cells to lung hypoxia-reperfusion injury. The exposure of endothelial cells to activated AMOs media enhances chemokine secretion in response to hypoxia and reoxygenation. In the reciprocal experiment, activated endothelial cell media increased the production of MCP-1 from macrophages. AMOs propel the development of lung reperfusion injury by enhancing the production of proinflammatory chemokines from endothelial cells, which in turn imparts a degree of positive feedback on AMOs. This suggests that the activation of AMOs may induce vascular endothelial cells to regulate an inflammatory response in the lungs to alveolar hypoxia. 
Alveolar hypoxia triggers specific hemodynamic effects during pulmonary circulation, which results in leukocyte recruitment to the lungs. Exposure to alveolar hypoxia leads to pulmonary arterial constriction within seconds and elevates pulmonary arterial pressure. Even a modest elevation of lung vascular pressure has been shown to activate pro-inflammatory responses in endothelial cells of the lung venular capillaries, including Pselectin upregulation [80], and increased production of reactive oxygen species (ROS) [81]. In addition, the pulmonary interstitium around the bronchus and vessels also hosts macrophages and DCs. These cells can be activated by alveolar hypoxia through the mechanical effects of vascular constriction and certain mediators secreted by vascular endothelial cells. Otherwise, hypoxia may exert different effects on chemokine and/or adhesion molecule expression in bronchial versus pulmonary arterial endothelial cells. Part of the bronchial circulatory system, such as the vasa vasorum, may also serve as a major portal for leukocyte entry into hypoxic lungs. However, these concepts are still unclear.

Taken together, experimental data suggest that alveolar hypoxia induces pulmonary inflammation at local sites through AMO activation and subsequent interactions with other resident lung cells. Consequently, those localized reactions create a proinflammatory microenvironment in the lungs, which then evokes a predominant chemotactic effect that allows a specific recruitment of inflammatory cells to the lungs (as shown in Fig. 1).

However, the main cell type that migrates to the pulmonary vessel wall originates from the bloodstream and the distribution is enlarged by the duration of hypoxia exposure $[82,83]$. This suggests that alveolar hypoxiainduced local inflammatory responses of the lungs may trigger another series of processes that aggravate pulmonary inflammation, characterized as the progressed accumulation of bloodstream leukocytes in the lung, which induces acute lung injury during acute phases of hypoxia, or pulmonary vascular remodeling under chronic hypoxia conditions.

\section{AMOs Are Required for Systemic Inflammation under Alveolar Hypoxia Conditions}

As mentioned above, massive leukocytes that accumulate in the pulmonary artery originate from the bloodstream, which can be confirmed by CD45 and CD11b stains. This suggests that a widespread, systemic inflammatory response is involved in the pulmonary inflamma- tion induced by alveolar hypoxia. There is mounting evidence that reduced alveolar $\mathrm{PO}_{2}$ levels result in rapid, systemic inflammation characterized by ROS generation, mast cell degranulation, leukocyte-endothelial interactions, increased vascular permeability, and cell infiltration. Rats breathing $10 \% \mathrm{O}_{2}$ show a rapid inflammatory response in mesentery, skeletal muscle, and pial microcirculations within minutes of hypoxia onset $[40,84,85]$. However, mast cell degranulation and leukocyte recruitment occur only when the alveolar $\mathrm{PO}_{2}$ level is reduced, independent of the systemic $\mathrm{PO}_{2}$ level in skeletal muscle [84]. Cultured peritoneal mast cells did not show degranulation under low oxygen conditions. Immersion of mast cells in a supernatant of hypoxic AMOs, but not in that from hypoxic peritoneal macrophages, induces mast cell degranulation [26]. Interestingly, hypoxia induced a respiratory burst in alveolar, but not peritoneal, macrophages [26]. This suggests that AMO activation is required for alveolar hypoxia-induced systemic inflammation.

Systemic inflammation under alveolar hypoxia conditions is modulated by inflammatory mediators, which are released by AMOs. Studies by Chao et al. [26-28, 86] confirm that alveolar hypoxia-induced systemic inflammation requires $\mathrm{AMO}$ activation, independent of reduced systemic $\mathrm{PO}_{2}$ levels or the activation of tissue macrophages. Another study found that plasma from alveolar hypoxic rats evokes an inflammatory response in tissues of normoxic rats, which suggests that a mediator released by hypoxic AMOs activates mast cells and triggers systemic inflammation [87]. Further research by the same group showed that systemic inflammation is initiated by circulating MCP-1, which is released from activated AMOs at low alveolar $\mathrm{PO}_{2}$ levels. Circulating MCP-1 induces mast cell degranulation with renin release and activation of the local renin-angiotensin system (RAS), leading to microvascular leukocyte recruitment and increased vascular permeability [28].

A study using AMO-depleted, hypoxic rats provided direct evidence that AMO activation is required for the initiation of systemic inflammation. The supernatant of hypoxic AMO, but not of hypoxic systemic tissue macrophages, induced mast cell degranulation in vivo and in vitro [87]. Mast cells undergo degranulation when immersed in plasma from intact hypoxic rats, but not in plasma from AMO-depleted hypoxic rats [28]. Lastly, plasma MCP-1 concentration increases rapidly in rats breathing $10 \% \mathrm{O}_{2}$, but does not increase in AMO-depleted rats [87]. MCP-1 induces a concentration-dependent mast cell degranulation, and administration to normoxic 
rats results in hypoxia-induced inflammation. Conversely, an MCP-1 receptor antagonist blocks alveolar hypoxia-induced systemic inflammation in intact rats. This is consistent with previous observations that AMO depletion prevents alveolar hypoxia-induced systemic inflammation, and that plasma from intact hypoxic rats, but not of AMO-depleted rats, elicits inflammation in normoxic tissues $[28,88]$.

In vitro experiments have shown that the permeability of single-layer endothelial cells and leukocyte-endothelial cell adhesion are induced under low oxygen conditions. This is not consistent with the above results showing that AMOs are necessary for alveolar hypoxia-induced systemic inflammation. However, different phases of alveolar hypoxia can explain this discrepancy. It was previously shown that alveolar hypoxia induces systemic inflammation within several minutes [27], although systemic $\mathrm{PO}_{2}$ levels do not demonstrate obvious changes. With prolonged exposure to low alveolar $\mathrm{PO}_{2}$ levels, systemic oxygen pressure decreases and exerts further effects on systemic inflammation. This suggests that AMOs trigger specific effects during the acute phase of hypoxia that are necessary for the initiation of systemic inflammation. However, other possibilities should be considered. Although most cell types are cultured under $21 \%$ oxygen conditions, it may not be appropriate to set $21 \%$ oxygen as a normoxic control. First, cells cultured in $21 \%$ oxygen conditions proliferate continuously and much faster than their physiological state in vivo. Second, oxygen pressure decreases in a gradient from alveoli to internal organs [30, 89]. It is impossible for blood to contain the same oxygen pressure as air. For example, it has been demonstrated that oxygen pressure in small arterioles is about 30-40 $\mathrm{mm} \mathrm{Hg}$ under normoxic conditions [30]. According to Dalton's law, oxygen concentration is related to oxygen pressure; therefore, oxygen concentration at small arterioles is approximately $5 \%$. If data from in vitro and in vivo experiments are compared, selection of oxygen levels characteristic of normoxic conditions is critical for prospective analyses. However, this issue is still under investigation.

\section{Activated Systemic Inflammation Is Critical for the Progression of Pulmonary Inflammation and HPH Development}

Inhibition of systemic inflammation prevents hypoxic pulmonary inflammation, and then attenuates $\mathrm{HPH}$ development. Dexamethasone treatment at any key step of the inflammatory cascade results in significant inhibition of pulmonary inflammatory responses induced by alveolar hypoxia $[90,91]$. A recent report has shown that lungspecific expression of heme oxygenase-1 (HO-1) may confer protection from $\mathrm{HPH}$ by effectively modifying the macrophage activation state during hypoxia. However, a brief, 2-day expression of high levels of $\mathrm{HO}-1$ delayed, but did not prevent, the peak of hypoxic inflammation, and could not protect against HPH. In contrast, a 7-day expression of high levels of HO-1 during an entire period of hypoxic inflammation inhibited macrophage accumulation and activation, and prevented HPH development [92]. This suggests that alveolar hypoxia-induced systemic inflammation is crucial for the progression of pulmonary inflammation and HPH development in chronic hypoxia. The possible mechanisms are discussed below.

\section{Activated Systemic Inflammation Prolongs the \\ Accumulation of Monocytes in the Lungs by \\ Promoting Cell Adhesion and Transendothelium \\ Migration}

Bloodstream leukocytes enter the pulmonary circulation and pulmonary vasculature system through the vascular endothelium. Interruption of leukocyte-endothelial cell interactions or protection against endothelium hyperpermeability attenuates hypoxia-induced inflammatory cell infiltration. Iptakalim is an adenosine triphosphate-sensitive potassium channel opener [93]. One study found that iptakalim prevented an increase in IL- $1 \beta$ and a decrease in IL-10 in the peripheral blood and lung tissue, and alleviated inflammatory cell infiltration in rats with HPH [94]. Furthermore, iptakalim enhanced PECAM-1 and eNOS expression and prevented endothelial cell injury induced by hypoxic stimuli. Finally, increases in the mean pulmonary artery pressure, right ventricular systolic pressure, right ventricle to left ventricle plus septum ratio, and small pulmonary artery wall remodeling in HPH rats were attenuated. This suggests that suppression of pulmonary arterioles and systemic inflammatory responses and protection against endothelial damage are critical for the inhibition of HPH development.

Mast cells are known to increase in number at sites of inflammation, where they are believed to influence vascular permeability, cell accumulation, and tissue-specific responses [95]. Under hypoxic conditions, activated mast cells are involved in vascular hyperpermeability and leukocyte cell-endothelium adhesion. The activation of mast cells with compound 48/80 under normoxic conditions produced microvascular effects similar to those under hypoxic conditions. The blockade of mast cell degranula- 
tion with cromolyn prevented or attenuated hypoxia-induced increases in ROS, leukocyte adherence/emigration, and vascular permeability [96].

An activated RAS mediates microvascular inflammation by increasing leukocyte-endothelial interactions and vascular hyperpermeability $[86,97]$. It has been reported that MCP-1-induced MC degranulation is involved in RAS activation under alveolar hypoxia [86]. Western blots and immunocytochemistry demonstrated the presence of renin and angiotensin-converting enzyme in mast cells and their release upon degranulation. MCP-1-induced degranulation of mast cells incubated in plasma produced an increase in angiotensin II concentration, which was inhibited completely by the MCP-1 receptor antagonist RS-102895, the specific rat renin inhibitor WFML, or the angiotensin-converting enzyme inhibitor captopril. Captopril also inhibited angiotensin II generation by the incubation of mast cells in culture medium containing angiotensin I. The results show that peritoneal mast cells contain active renin, which activates the RAS upon degranulation.

Vascular endothelial growth factor (VEGF) has been implicated to contribute to tissue edema through its effect on vascular permeability. Hypoxia induces VEGF production by endothelial cells, which contributes to angiogenesis and vascular hyperpermeability. Recent research found that mast cells modulate VEGF levels under hypoxic conditions. A study revealed that the expression of VEGF, Flt-1, and Flk-1 increased significantly when myocardial microvascular endothelial cells were cocultured with mast cell granules or active mast cells [98]. It is interesting that mast cells are a source of VEGF secretion. Cobalt chloride $\left(\mathrm{CoCl}_{2}\right)$, a hypoxia-mimicking agent, promotes a sustained production of functional VEGF from mast cells and induces proliferation of endothelial cells in vitro [99].

\section{Activated Systemic Inflammation Promotes Vascular Remodeling}

Vascular remodeling is associated with collagenolysis and the activation of matrix metalloproteinases (MMPs). One of the possible sources of MMPs in hypoxic lung is mast cells. In order to define the role of lung mast cell collagenolytic activity in $\mathrm{HPH}$, rats were treated with the inhibitor of mast cell degranulation disodium cromoglycate, DSCG, in an early or later phase of isobaric hypoxia. Lung hemodynamics, muscularization, and collagen metabolism in the walls of peripheral pulmonary vessels were measured. This study found that DSCG applied at an early phase of exposure to hypoxia inhibited muscu-

Alveolar Hypoxia-Induced Pulmonary

Inflammation larization in peripheral pulmonary arteries and decreased the amount of collagen cleavage fragments in prealveolar vessels $[100,101]$. This suggests that mast cell degranulation plays a role in the initiation of hypoxic pulmonary vascular remodeling.

It has also revealed that activated mast cells are participated in pulmonary artery remodeling $[102,103]$. Exposure to acute hypoxia (barometric pressure of $263 \mathrm{~mm}$ $\mathrm{Hg}$ ) for $8 \mathrm{~h}$ did not lead to increased numbers of mast cells in rat lungs. In contrast, adult rats maintained at a barometric pressure of $380 \mathrm{~mm} \mathrm{Hg}$ for 35 days exhibit a proliferation of mast cells around pulmonary blood vessels and in alveolar septa. There is a correlation between perivascular lung mast cell density and medial thickness of muscular pulmonary arteries [104]. The MMP family of proteolytic enzymes is involved in remodeling of the extracellular matrix. Although proteolytic enzymes are produced by many cell types (mast cells, fibroblasts, vascular smooth muscle cells, and endothelial cells), mast cells are the most abundant source of proteolytic enzymes under normoxic and hypoxic conditions [105]. In order to verify that chronic hypoxia-induced vascular remodeling is initiated in the walls of prealveolar pulmonary arteries by MMPs released from activated mast cells, the distribution of mast cells and their expression of interstitial collagenase, MMP-13, in lung conduit, small muscular, and prealveolar arteries were examined in rats exposed to hypoxia for 4 and 20 days, as well as after a 7-day recovery from 20 -day hypoxia $\left(10 \% \mathrm{O}_{2}\right)$. After 4 days, but not after 20 days of hypoxia, the number of mast cells increased significantly, and MMP-13 expression was found within prealveolar artery walls. In rats exposed to hypoxia for 20 days, MMP-13-positive mast cells accumulated within the walls of conduit arteries as well as subpleurally. In recovered rats, MMP-13-positive mast cells gather at prealveolar artery walls and in the walls of small muscular arteries. These mast cells also remained in the conduit part of the pulmonary vasculature [106]. This suggests that perivascular pulmonary mast cells contribute to vascular remodeling in rats by releasing interstitial collagenase.

ROS are important mediators of the proliferation response in pulmonary vascular cells. ROS increase the expression and/or activation of multiple factors involved in cellular growth, including PI3K/Akt, p38MAPK, c-Src, TGF- $\beta 1$, VEGF, PDGF, FGF-2, NFAT (nuclear factor of activated T cells), and PGC-1 $\alpha$ (peroxisome proliferatoractivated receptor- $\gamma$ coactivator $1 \alpha$ ). All these factors have been implicated in pulmonary vascular remodeling $[107,108]$. ROS-dependent fluorescence is induced within minutes of hypoxia onset, and is observed in perivas- 


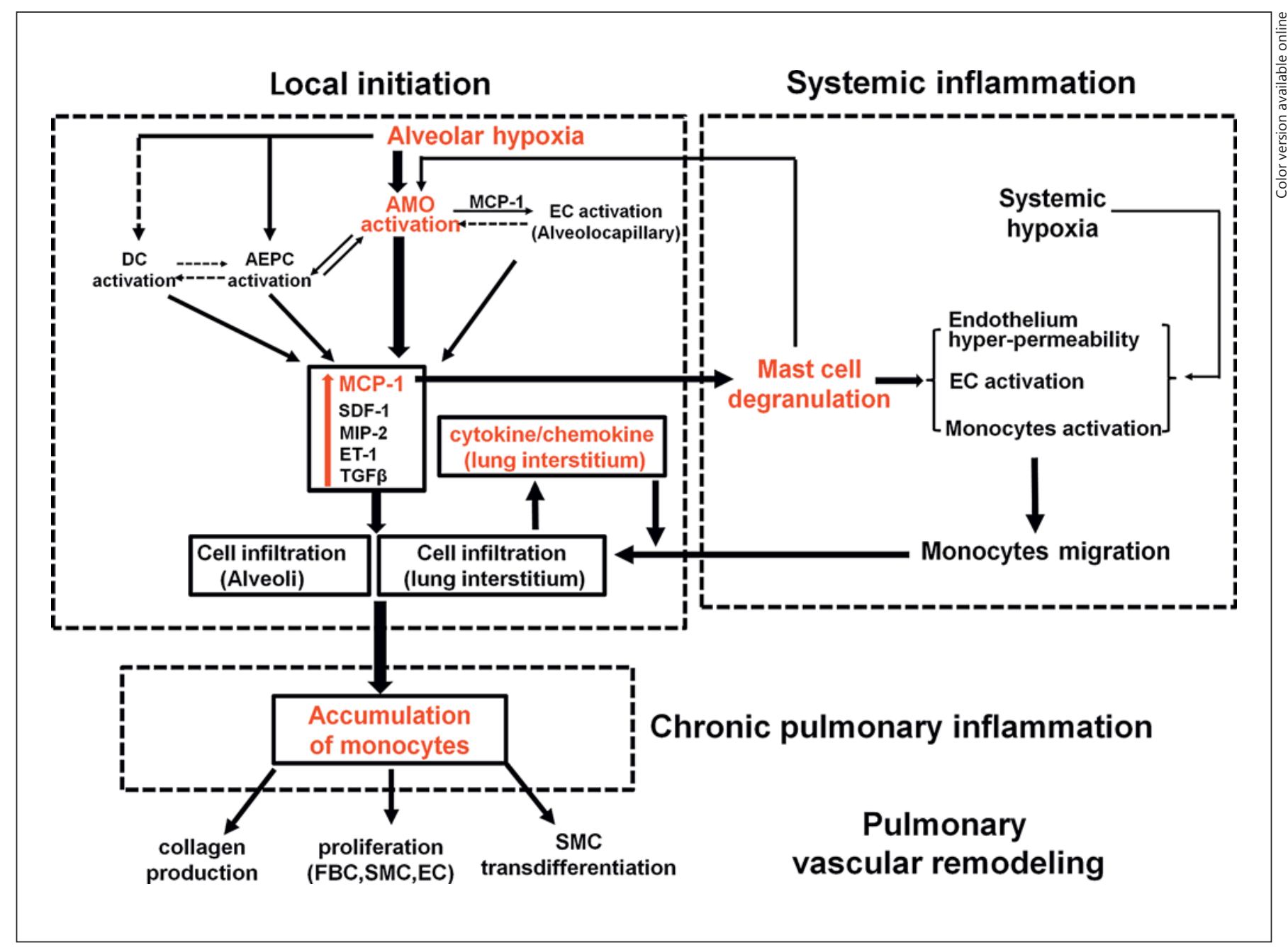

Fig. 1. The initiation and progression of alveolar hypoxia-induced pulmonary inflammation. EC, endothelial cell; ET-1, endothelin-1; FBC, fibroblast cell; SMC, smooth muscle cell.

cular mast cells in endothelial layers of postcapillary venules, and at the sites of leukocyte-endothelial interactions [96, 109]. The magnitudes of ROS-dependent fluorescence intensity and leukocyte-endothelial interactions are inversely related to $\mathrm{PO}_{2}$ values [110]. The antioxidants SOD/catalase and lipoic acid significantly inhibit ROS-dependent fluorescence intensity and increased leukocyte-endothelial interactions $[96,109]$.

Taken together, a secondary activation of systemic inflammation under alveolar hypoxia conditions is essential for the progression of pulmonary inflammation and $\mathrm{HPH}$ development, which is shown in Figure 1. However, studies in mast cell-deficient mice demonstrated that there were no obvious differences in the pulmonary re- sponses of these mice and normal mice to alveolar hypoxia, since the right ventricular peak systolic pressure, the right ventricular hypotrophy index, and the pulmonary arterial structure had similar changes under chronic alveolar hypoxia conditions [111]. In this report, a mast cell-deficient mouse had less than $1 \%$ of the normal number of mast cells in the skin, stomach, cecum, and mesentery, and had no lung mast cells. Tissue mast cells are the main source of histamine, which is an important mediator for pulmonary responses to hypoxia. However, histamine content in mast cell-deficient and normal mouse lungs was similar. This implies that systemic inflammation alone is not sufficient to induce pulmonary inflammation and $\mathrm{HPH}$ under alveolar hypoxia. 


\section{A Combination of Alveolar Hypoxia-Induced Lung Local Inflammation and a Secondary Activation of Systemic Inflammation Controls Monocyte Infiltration in the Lungs}

For the migration of blood-derived leukocytes into ischemic or hypoxic tissues, a series of events must occur. Leukocytes are activated and adhere to endothelial cells. Then, the transendothelium migrates and arrives at its destination by chemotactic effects. As discussed above, most of the inflammatory cells that accumulate in pulmonary circulation under alveolar hypoxia conditions are bloodstream mononuclear cell types. Their accumulation and retention is specific in pulmonary perivascular regions, while it is undetectable, or only minimally increased, at the adjoining lung parenchyma and systemic arteries (aorta and renal artery). These migrant cells are essential in the development of hypoxia-induced pulmonary vascular remodeling, which has been reviewed in detail previously $[66,83,92]$. Therefore, the mechanism for the specific recruitment and retention of these cells in the pulmonary vasculature under alveolar hypoxia conditions is necessary for the understanding of $\mathrm{HPH}$ initiation and development. Published evidence has been summarized that supports a combination of alveolar hypoxiainduced local lung inflammation and the initiation of systemic inflammation ("second hit") that is necessary for the accumulation of bloodstream mononuclear cells in the lungs.

Alveolar Hypoxia-Induced Local Inflammation Evokes a Chemotactic Effect That Directs the Recruitment of

Bloodstream Monocytes to the Lungs

It is well known that the primary step in leukocyte migration is the establishment of weak and transient adhesive interactions between leukocytes and vascular endothelial cells. However, the cues that regulate the site and route of monocyte migration along and through the endothelial cell barrier are critical since alveolar hypoxiainduced monocyte infiltration is specific to pulmonary circulation. This suggests that primary chemotactic signals exist in the lungs and determine the site of leukocyte migration into the lungs.

In order to identify potential mediators that are responsible for recruitment of circulating cells within the hypoxic pulmonary artery, mRNA expression of 44 different chemokine/chemokine receptor, cytokine, adhesion, growth, and differentiation genes in pulmonary arteries was examined by RT-PCR at several time points of hypoxic exposure (1, 7, and 28 days) in Wistar-Kyoto rats

Alveolar Hypoxia-Induced Pulmonary

Inflammation
[25]. Samples were obtained via laser capture microdissection in adjacent lung parenchyma and in systemic arteries. Consistent with other reports, this study also found that hypoxia induced the progressive accumulation of monocytes and DCs in the vessel wall with few $\mathrm{T}$ cells and no B cells or neutrophils. Upregulation of stromal cellderived factor-1 (SDF-1), VEGF, GRO- $\alpha$ (growth-related oncogene protein- $\alpha$ ), C5, ICAM-1, OPN (osteopontin), and TGF- $\beta$ (transforming growth factor- $\beta$ ) preceded mononuclear cell influx. With time, a more complex pattern of gene expression developed with the persistent upregulation of adhesion molecules (ICAM-1, VCAM-1, and $\mathrm{OPN}$ ) and monocyte/fibrocyte growth and differentiation factors (TGF- $\beta$, endothelin-1, and 5-lipoxygenase). On return to normoxia, expression of many genes (including SDF-1, MCP-1, C5, ICAM-1, and TGF- $\beta$ ) rapidly returned to control levels, changes that preceded the disappearance of monocytes and reversal of vascular remodeling. This suggests that sustained hypoxia leads to the development of a complex, pulmonary artery-specific, proinflammatory microenvironment capable of promoting the recruitment and retention of circulating monocytic cell populations that contribute to vascular remodeling.

The source of inflammatory factors in the lungs under alveolar hypoxia conditions is still under investigation. A local, activated lung cell, AMO, is a producer of inflammatory factors during the acute phase of alveolar hypoxia $[1,10,62,63,68,76,78,92,112-116]$. The distribution of leukocytes or migration of blood-derived leukocytes at the pulmonary artery is diminished remarkably after AMO clearance. AMOs actively secrete cytokines and chemokines, such as MCP-1, IL-6, and 5-HT, under hypoxic conditions. Among them, MCP-1 is indispensable for the development of alveolar hypoxia-induced lung local inflammation and systemic inflammation. If AMOderived MCP-1 production decreases, the distribution of leukocytes in the lungs is reduced. In this regard, the preinflammatory condition is initiated by local cell activation, which may be related to a hyperactive lung's inflammatory response to alveolar hypoxia.

\section{Activated Mast Cells Stimulate AMOs to Induce Monocyte Chemotactic Activity}

Histamine is an important mediator for pulmonary responses to hypoxia [117-123]. Tissue mast cells are the main producer of histamine. AMOs secrete histaminereleasing factors, which induces histamine release by mast cells and basophils [124]. Furthermore, AMOs themselves are affected by histamine by the expression of 
the histamine receptors $\mathrm{H} 1$ and $\mathrm{H} 2$ [125-127]. This suggests that activated systemic inflammation influences the function of AMOs through feedback.

Increasing evidence suggests that a continuous release of histamine from mast cells may modulate the functions of macrophages. Histamine induces exocytosis and IL-6 production from human lung macrophages through interaction with $\mathrm{H} 1$ receptors. Increases in histamine levels $\left(10^{9}-10^{6} \mathrm{M}\right)$ in a concentration-dependent fashion result in the basal release of $\beta$-glucuronidase and IL- 6 from human lung macrophages. Enhancement of $\beta$-glucuronidase release induced by histamine was evident after $30 \mathrm{~min}$ and peaked at $90 \mathrm{~min}$, whereas that of IL- 6 required 2-6 h of incubation. These effects were reproduced by an $\mathrm{H} 1$ agonist but not by an $\mathrm{H} 2$ agonist [127]. This suggests that histamine induces exocytosis and IL-6 production from human macrophages by activation of the $\mathrm{H} 1$ receptor, which contributes to the long-term sustainment of pulmonary inflammation.

More importantly, histamine stimulates AMOs to induce neutrophil and monocyte chemotactic activity [126]. In one study, bovine AMOs were cultured and supernatant fluids were evaluated for neutrophil chemotactic activity and monocyte chemotactic activity using a blindwell chamber technique. AMOs induced chemotactic activity in response to histamine in a dose- and time-dependent manner. Partial characterization and molecular sieve column chromatography revealed that low-molecular-weight lipid-soluble activity was predominant. Lipoxygenase inhibitors significantly blocked the induction of chemotactic activity. Leukotriene B4 receptor antagonists blocked the chemotactic activity. Immunoreactive leukotriene B4 significantly increased in supernatant fluids in response to histamine. The receptor responsible for the induction of chemotactic activity in response to histamine was the $\mathrm{H} 2$ receptor. These data demonstrate that AMOs release neutrophil and monocyte chemotactic activity in response to histamine and may thereby modulate inflammatory cell recruitment into the lungs.

\section{Conclusion}

Accumulated evidence supports the idea that continued recruitment of circulating monocytes into pulmonary circulation may play an important role in the development of $\mathrm{PH}$ in response to both acute and chronic alveolar hypoxia. However, the mechanisms responsible for leukocyte recruitment and migration into the pulmonary vasculature under alveolar hypoxia remain under investigation. In this review, we have discussed a series of studies that support the hypothesis that alveolar hypoxia induces a localized inflammatory response in the lung and a subsequent systemic inflammation (as a "second hit"), both of which are combined and essential to HPH development. As shown in Figure 1, alveolar hypoxia creates an inflammatory microenvironment in the lungs specifically, which triggers chemotactic effects on circulating monocytes to accumulate at the pulmonary vasculature. A secondary activation of systemic inflammation is necessary to trigger and allow monocyte migration into the lungs. A better understanding of the initiation and progression of alveolar hypoxia-induced pulmonary inflammation may lead to the identification of novel targets that could inhibit HPH development.

\section{Acknowledgements}

We thank Prof. Guilian Xu for the preparation of the manuscript. We thank the other members of our department for their suggestions during the course of this work.

This work was supported by the National Natural Science Foundation of China (grant No. 30971198; 81270108) and the National Basic Research Program of China (973 Program, grant No. 2012CB518201).

\section{Disclosure Statement}

The authors have no conflicts of interest to report.

\section{References}

1 Pugliese SC, Poth JM, Fini MA, Olschewski A, El Kasmi KC, Stenmark KR: The role of inflammation in hypoxic pulmonary hypertension: from cellular mechanisms to clinical phenotypes. Am J Physiol Lung Cell Mol Physiol 2015;308:L229-L252.

2 Strielkov IV, Frantsuzova SB, Khromov OS: Hypoxic pulmonary hypertension: modern views on pathogenesis and options for rational pharmacological correction (in Ukrainian). Fiziol Zh 2012;58:89-100.
3 Vender RL: Chronic hypoxic pulmonary hypertension: cell biology to pathophysiology. Chest 1994;106:236-243.

4 Pugliese SC, Poth JM, Fini MA, Olschewski A, El Kasmi KC, Stenmark KR: The Role of inflammation in hypoxic pulmonary hypertension: from cellular mechanisms to clinical phenotypes. Am J Physiol Lung Cell Mol Physiol 2015;308:L229-L252. 
5 Welsh DJ, Peacock AJ: Cellular responses to hypoxia in the pulmonary circulation. High Alt Med Biol 2013;14:111-116.

6 Zhou L, Wang LM, Song HM, Shen YQ, Xu WJ, Xu JH, Liu Y, Yan WW, Jiang JF: Expression profiling analysis of hypoxic pulmonary disease. Genet Mol Res 2013;12:4162-4170.

7 Swenson ER: Hypoxic pulmonary vasoconstriction. High Alt Med Biol 2013;14:101-110.

8 Ward JP, McMurtry IF: Mechanisms of hypoxic pulmonary vasoconstriction and their roles in pulmonary hypertension: new findings for an old problem. Curr Opin Pharmacol 2009;9:287-296.

9 Olson KR, Whitfield NL, Bearden SE, St Leger J, Nilson E, Gao Y, Madden JA: Hypoxic pulmonary vasodilation: a paradigm shift with a hydrogen sulfide mechanism. Am J Physiol Regul Integr Comp Physiol 2010;298:R51-R60.

10 Madjdpour C, Jewell UR, Kneller S, Ziegler U, Schwendener R, Booy C, Klausli L, Pasch T, Schimmer RC, Beck-Schimmer B: Decreased alveolar oxygen induces lung inflammation. Am J Physiol Lung Cell Mol Physiol 2003; 284:L360-L367.

11 Murdoch C, Muthana M, Lewis CE: Hypoxia regulates macrophage functions in inflammation. J Immunol 2005;175:6257-6263.

12 Chaouat A, Naeije R, Weitzenblum E: Pulmonary hypertension in COPD. Eur Respir J 2008;32:1371-1385.

13 Ryan S, McNicholas WT: Intermittent hypoxia and activation of inflammatory molecular pathways in OSAS. Arch Physiol Biochem 2008;114:261-266.

14 Chaouat A, Savale L, Chouaid C, Tu L, Sztrymf B, Canuet M, Maitre B, Housset B, Brandt C, Le Corvoisier P, Weitzenblum E, Eddahibi S, Adnot S: Role for interleukin-6 in COPD-related pulmonary hypertension. Chest 2009;136:678-687.

15 Flamant L, Toffoli S, Raes M, Michiels C: Hypoxia regulates inflammatory gene expression in endothelial cells. Exp Cell Res 2009; 315733-747.

16 Winning S, Splettstoesser F, Fandrey J, Frede S: Acute hypoxia induces HIF-independent monocyte adhesion to endothelial cells through increased intercellular adhesion molecule- 1 expression: the role of hypoxic inhibition of prolyl hydroxylase activity for the induction of NF-кB. J Immunol 2010;185: 1786-1793.

17 Schaible B, Schaffer K, Taylor CT: Hypoxia, innate immunity and infection in the lung. Respir Physiol Neurobiol 2010;174:235-243.

18 Eltzschig HK, Carmeliet P: Hypoxia and inflammation. N Engl J Med 2011;364:656-665.

19 Brusselle GG, Joos GF, Bracke KR: New insights into the immunology of chronic obstructive pulmonary disease. Lancet 2011; 378:1015-1026.

20 Wrobel JP, Thompson BR, Williams TJ: Mechanisms of pulmonary hypertension in chronic obstructive pulmonary disease: a pathophysiologic review. J Heart Lung Transplant 2012;31:557-564.
21 Zhang BL, Xu RL, Qin YW, Zheng X, Wu H, You XH, Cao J, Hu JQ, Zhao XX: Potential candidate genes for alveolar hypoxia identified by transcriptome network analysis. Medicina (Kaunas) 2012;48:572-580.

22 Frohlich S, Boylan J, McLoughlin P: Hypoxiainduced inflammation in the lung: a potential therapeutic target in acute lung injury? Am J Respir Cell Mol Biol 2013;48:271-279.

23 Whyte MK, Walmsley SR: The regulation of pulmonary inflammation by the hypoxiainducible factor-hydroxylase oxygen-sensing pathway. Ann Am Thorac Soc 2014;11(suppl 5):S271-S276.

24 Frid MG, Li M, Gnanasekharan M, Burke DL, Fragoso M, Strassheim D, Sylman JL, Stenmark KR: Sustained hypoxia leads to the emergence of cells with enhanced growth, migratory, and promitogenic potentials within the distal pulmonary artery wall. Am J Physiol Lung Cell Mol Physiol 2009;297:L1059-L1072.

25 Burke DL, Frid MG, Kunrath CL, Karoor V, Anwar A, Wagner BD, Strassheim D, Stenmark KR: Sustained hypoxia promotes the development of a pulmonary artery-specific chronic inflammatory microenvironment. Am J Physiol Lung Cell Mol Physiol 2009; 297:L238-L250.

26 Chao J, Wood JG, Blanco VG, Gonzalez NC: The systemic inflammation of alveolar hypoxia is initiated by alveolar macrophageborne mediator(s). Am J Respir Cell Mol Biol 2009;41:573-582.

27 Chao J, Wood JG, Gonzalez NC: Alveolar macrophages initiate the systemic microvascular inflammatory response to alveolar hypoxia. Respir Physiol Neurobiol 2011;178:439-448.

28 Chao J, Donham P, van Rooijen N, Wood JG, Gonzalez NC: Monocyte chemoattractant protein-1 released from alveolar macrophages mediates the systemic inflammation of acute alveolar hypoxia. Am J Respir Cell Mol Biol 2011;45:53-61.

29 Sakao S, Tatsumi K, Voelkel NF: Reversible or irreversible remodeling in pulmonary arterial hypertension. Am J Respir Cell Mol Biol 2010; 43:629-634.

30 Tsai AG, Friesenecker B, Mazzoni MC, Kerger $\mathrm{H}$, Buerk DG, Johnson PC, Intaglietta M: Microvascular and tissue oxygen gradients in the rat mesentery. Proc Natl Acad Sci USA 1998;95:6590-6595.

31 Hyman AL, Higashida RT, Spannhake EW, Kadowitz PJ: Pulmonary vasoconstrictor responses to graded decreases in precapillary blood $\mathrm{PO}_{2}$ in intact-chest cat. J Appl Physiol Respir Environ Exerc Physiol 1981;51:10091016.

32 Evans AM, Hardie DG, Peers C, Mahmoud A: Hypoxic pulmonary vasoconstriction: mechanisms of oxygen-sensing, Curr Opin Anaesthesiol 2011;24:13-20.

33 Teng X, Li D, Champion HC, Johns RA: FIZZ1/RELMa, a novel hypoxia-induced mitogenic factor in lung with vasoconstrictive and angiogenic properties. Circ Res 2003;92: 1065-1067.
34 Angelini DJ, Su Q, Yamaji-Kegan K, Fan C, Skinner JT, Champion HC, Crow MT, Johns RA: Hypoxia-induced mitogenic factor (HIMF/FIZZ1/RELMa) induces the vascular and hemodynamic changes of pulmonary hypertension. Am J Physiol Lung Cell Mol Physiol 2009;296:L582-L593.

35 Yamaji-Kegan K, Su Q, Angelini DJ, Myers AC, Cheadle C, Johns RA: Hypoxia-induced mitogenic factor (HIMF/FIZZ1/RELM $\alpha$ ) increases lung inflammation and activates pulmonary microvascular endothelial cells via an IL-4-dependent mechanism. J Immunol 2010;185:5539-5548.

36 Angelini DJ, Su Q, Yamaji-Kegan K, Fan C, Skinner JT, Poloczek A, El-Haddad H, Cheadle C, Johns RA: Hypoxia-induced mitogenic factor (HIMF/FIZZ1/RELM $\alpha$ ) in chronic hypoxia- and antigen-mediated pulmonary vascular remodeling. Respir Res 2013;14:1.

37 Yamaji-Kegan K, Takimoto E, Zhang A, Weiner NC, Meuchel LW, Berger AE, Cheadle C, Johns RA: Hypoxia-induced mitogenic factor (FIZZ1/RELMa) induces endothelial cell apoptosis and subsequent interleukin4-dependent pulmonary hypertension. Am J Physiol Lung Cell Mol Physiol 2014; 306:L1090-L1103.

38 Costello CM, Howell K, Cahill E, McBryan J, Konigshoff M, Eickelberg O, Gaine S, Martin F, McLoughlin P: Lung-selective gene responses to alveolar hypoxia: potential role for the bone morphogenetic antagonist gremlin in pulmonary hypertension. Am J Physiol Lung Cell Mol Physiol 2008;295:L272-L284.

39 Cahill E, Costello CM, Rowan SC, Harkin S, Howell K, Leonard MO, Southwood M, Cummins EP, Fitzpatrick SF, Taylor CT, Morrell NW, Martin F, McLoughlin P: Gremlin plays a key role in the pathogenesis of pulmonary hypertension. Circulation 2012;125:920-930.

40 Wood JG, Mattioli LF, Gonzalez NC: Hypoxia causes leukocyte adherence to mesenteric venules in nonacclimatized, but not in acclimatized, rats. J Appl Physiol 1999;87:873-881.

41 Minamino T, Christou H, Hsieh CM, Liu Y, Dhawan V, Abraham NG, Perrella MA, Mitsialis SA, Kourembanas S: Targeted expression of heme oxygenase-1 prevents the pulmonary inflammatory and vascular responses to hypoxia. Proc Natl Acad Sci USA 2001;98: 8798-8803.

42 Kubo K, Hanaoka M, Hayano T, Miyahara T, Hachiya T, Hayasaka M, Koizumi T, Fujimoto K, Kobayashi T, Honda T: Inflammatory cytokines in BAL fluid and pulmonary hemodynamics in high-altitude pulmonary edema. Respir Physiol 1998;111:301-310.

43 Swenson ER, Bartsch P: High-altitude pulmonary edema. Compr Physiol 2012;2:27532773.

44 Hartmann G, Tschop M, Fischer R, Bidlingmaier C, Riepl R, Tschop K, Hautmann H, Endres S, Toepfer M: High altitude increases circulating interleukin-6, interleukin-1 receptor antagonist and C-reactive protein. Cytokine 2000;12:246-252. 
45 Dorfmuller P, Perros F, Balabanian K, Humbert M: Inflammation in pulmonary arterial hypertension, Eur Respir J 2003;22:358-363.

46 Price LC, Wort SJ, Perros F, Dorfmuller P, Huertas A, Montani D, Cohen-Kaminsky S, Humbert M: Inflammation in pulmonary arterial hypertension. Chest 2012;141:210-221.

47 Kherbeck N, Tamby MC, Bussone G, Dib H, Perros F, Humbert M, Mouthon L: The role of inflammation and autoimmunity in the pathophysiology of pulmonary arterial hypertension. Clin Rev Allergy Immunol 2013; 44:31-38.

48 Hassoun PM: Inflammation in pulmonary arterial hypertension: is it time to quell the fire? Eur Respir J 2014;43:685-688.

49 Sawano A, Iwai S, Sakurai Y, Ito M, Shitara K, Nakahata T, Shibuya M: Flt-1, vascular endothelial growth factor receptor 1 , is a novel cell surface marker for the lineage of monocytemacrophages in humans. Blood 2001;97:785791.

50 Lewis C, Murdoch C: Macrophage responses to hypoxia: implications for tumor progression and anti-cancer therapies. Am J Pathol 2005; 167:627-635.

51 Murdoch C, Lewis CE: Macrophage migration and gene expression in response to tumor hypoxia. Int J Cancer 2005;117:701-708.

52 Winner M, Leng L, Zundel W, Mitchell RA: Macrophage migration inhibitory factor manipulation and evaluation in tumoral hypoxic adaptation. Methods Enzymol 2007;435:355369.

53 Weigert A, Brune B: Nitric oxide, apoptosis and macrophage polarization during tumor progression. Nitric Oxide 2008;19:95-102.

54 Sica A, Allavena P, Mantovani A: Cancer related inflammation: the macrophage connection. Cancer Lett 2008;267:204-215.

55 Rendon BE, Willer SS, Zundel W, Mitchell RA: Mechanisms of macrophage migration inhibitory factor (MIF)-dependent tumor microenvironmental adaptation. Exp $\mathrm{Mol}$ Pathol 2009;86:180-185.

56 Rahat MA, Bitterman H, Lahat N: Molecular mechanisms regulating macrophage response to hypoxia. Front Immunol 2011;2:45.

57 Rahat MA, Hemmerlein B: Macrophagetumor cell interactions regulate the function of nitric oxide. Front Physiol 2013;4:144.

58 Maggiorini M, Melot C, Pierre S, Pfeiffer F, Greve I, Sartori C, Lepori M, Hauser M, Scherrer U, Naeije R: High-altitude pulmonary edema is initially caused by an increase in capillary pressure. Circulation 2001;103:2078-2083.

59 Swenson ER, Maggiorini M, Mongovin S, Gibbs JS, Greve I, Mairbaurl H, Bartsch P: Pathogenesis of high-altitude pulmonary edema: inflammation is not an etiologic factor. JAMA 2002;287:2228-2235.

60 Berg JT, Ramanathan S, Swenson ER: Inhibitors of hypoxic pulmonary vasoconstriction prevent high-altitude pulmonary edema in rats. Wilderness Environ Med 2004;15:32-37.

61 Sharma M, Singh SB, Sarkar S: Genome wide expression analysis suggests perturbation of vascular homeostasis during high altitude pulmonary edema. PLoS One 2014;9:e85902.

62 VanOtteren GM, Standiford TJ, Kunkel SL, Danforth JM, Strieter RM: Alterations of ambient oxygen tension modulate the expression of tumor necrosis factor and macrophage inflammatory protein- 1 alpha from murine alveolar macrophages. Am J Respir Cell Mol Biol 1995;13:399-409.

63 Wilhelm J, Sojkova J, Herget J: Production of hydrogen peroxide by alveolar macrophages from rats exposed to subacute and chronic hypoxia. Physiol Res 1996;45:185-191.

64 Wilhelm J, Vankova M, Maxova H, Siskova A: Hydrogen peroxide production by alveolar macrophages is increased and its concentration is elevated in the breath of rats exposed to hypoxia: relationship to lung lipid peroxidation. Physiol Res 2003;52:327-332.

65 Compeau CG, Ma J, DeCampos KN, Waddell TK, Brisseau GF, Slutsky AS, Rotstein OD: In situ ischemia and hypoxia enhance alveolar macrophage tissue factor expression. Am J Respir Cell Mol Biol 1994;11:446-455.

66 Stenmark KR, Davie NJ, Reeves JT, Frid MG: Hypoxia, leukocytes, and the pulmonary circulation. J Appl Physiol 2005;98:715-721.

67 Fernandez-Bustamante A, Klawitter J, Wilson P, Elkins ND, Agazio A, Shibata T, Uchida K, Christians U, Repine JE: Early increase in alveolar macrophage prostaglandin $15 \mathrm{~d}$ $\mathrm{PGJ}_{2}$ precedes neutrophil recruitment into lungs of cytokine-insufflated rats. Inflammation 2013;36:1030-1040.

68 Leeper-Woodford SK, Detmer K: Acute hypoxia increases alveolar macrophage tumor necrosis factor activity and alters NF- $\mathrm{kB}$ expression. Am J Physiol 1999;276:L909-L916.

69 Beck-Schimmer B, Schimmer RC, Madjdpour C, Bonvini JM, Pasch T, Ward PA: Hypoxia mediates increased neutrophil and macrophage adhesiveness to alveolar epithelial cells. Am J Respir Cell Mol Biol 2001;25:780-787.

70 Simon LM, Robin ED, Phillips JR, Acevedo J, Axline SG, Theodore J: Enzymatic basis for bioenergetic differences of alveolar versus peritoneal macrophages and enzyme regulation by molecular $\mathrm{O}_{2}$. J Clin Invest 1977;59:443-448.

71 Vermaelen K, Pauwels R: Pulmonary dendritic cells. Am J Respir Crit Care Med 2005;172: 530-551.

72 Kopf M, Schneider C, Nobs SP: The development and function of lung-resident macrophages and dendritic cells. Nat Immunol 2015;16:36-44.

73 Mancino A, Schioppa T, Larghi P, Pasqualini F, Nebuloni M, Chen IH, Sozzani S, Austyn JM, Mantovani A, Sica A: Divergent effects of hypoxia on dendritic cell functions. Blood 2008;112:3723-3734.

74 Thorley AJ, Goldstraw P, Young A, Tetley TD: Primary human alveolar type II epithelial cell CCL20 (macrophage inflammatory protein-3a)-induced dendritic cell migration. Am J Respir Cell Mol Biol 2005;32:262-267.

75 Fujii T, Hayashi S, Hogg JC, Mukae H, Suwa T, Goto Y, Vincent R, van Eeden SF: Interac- tion of alveolar macrophages and airway epithelial cells following exposure to particulate matter produces mediators that stimulate the bone marrow. Am J Respir Cell Mol Biol 2002; 27:34-41.

76 Hjort MR, Brenyo AJ, Finkelstein JN, Frampton MW, LoMonaco MB, Stewart JC, Johnston CJ, D'Angio CT: Alveolar epithelial cellmacrophage interactions affect oxygen-stimulated interleukin-8 release. Inflammation 2003;27:137-145.

77 Ishii H, Hayashi S, Hogg JC, Fujii T, Goto Y, Sakamoto N, Mukae H, Vincent R, van Eeden SF: Alveolar macrophage-epithelial cell interaction following exposure to atmospheric particles induces the release of mediators involved in monocyte mobilization and recruitment. Respir Res 2005;6:87.

78 Sharma AK, Fernandez LG, Awad AS, Kron IL, Laubach VE: Proinflammatory response of alveolar epithelial cells is enhanced by alveolar macrophage-produced TNF- $\alpha$ during pulmonary ischemia-reperfusion injury. Am J Physiol Lung Cell Mol Physiol 2007;293: L105-L113.

79 McCourtie AS, Merry HE, Farivar AS, Goss $\mathrm{CH}$, Mulligan MS: Alveolar macrophage secretory products augment the response of rat pulmonary artery endothelial cells to hypoxia and reoxygenation. Ann Thorac Surg 2008; 85:056-1060.

80 Kuebler WM, Ying X, Singh B, Issekutz AC, Bhattacharya J: Pressure is proinflammatory in lung venular capillaries. J Clin Invest 1999; 104:495-502.

81 Ichimura H, Parthasarathi K, Quadri S, Issekutz AC, Bhattacharya J: Mechano-oxidative coupling by mitochondria induces proinflammatory responses in lung venular capillaries. J Clin Invest 2003;111:691-699.

82 Frid MG, Brunetti JA, Burke DL, Carpenter TC, Davie NJ, Stenmark KR: Circulating mononuclear cells with a dual, macrophagefibroblast phenotype contribute robustly to hypoxia-induced pulmonary adventitial remodeling. Chest 2005;128:583S-584S.

83 Frid MG, Brunetti JA, Burke DL, Carpenter TC, Davie NJ, Reeves JT, Roedersheimer MT, van Rooijen N, Stenmark KR: Hypoxia-induced pulmonary vascular remodeling requires recruitment of circulating mesenchymal precursors of a monocyte/macrophage lineage. Am J Pathol 2006;168:659-669.

84 Shah S, Allen J, Wood JG, Gonzalez NC: Dissociation between skeletal muscle microvascular $\mathrm{PO}_{2}$ and hypoxia-induced microvascular inflammation. J Appl Physiol 2003;94: 2323-2329.

85 Chao J, Wood JG, Gonzalez NC: Alveolar hypoxia, alveolar macrophages, and systemic inflammation. Respir Res 2009;10:54.

86 Chao J, Blanco G, Wood JG, Gonzalez NC: Renin released from mast cells activated by circulating MCP-1 initiates the microvascular phase of the systemic inflammation of alveolar hypoxia. Am J Physiol Heart Circ Physiol 2011;301:H2264-H2270. 
87 Gonzalez NC, Allen J, Blanco VG, Schmidt EJ, van Rooijen N, Wood JG: Alveolar macrophages are necessary for the systemic inflammation of acute alveolar hypoxia. J Appl Physiol 2007;103:1386-1394.

88 Orth T, Allen JA, Wood JG, Gonzalez NC: Plasma from conscious hypoxic rats stimulates leukocyte-endothelial interactions in normoxic cremaster venules. J Appl Physiol 2005;99:290-297.

89 Zhuang J, Droma T, Sutton JR, Groves BM, McCullough RE, McCullough RG, Sun S, Moore LG: Smaller alveolar-arterial $\mathrm{O}_{2}$ gradients in Tibetan than Han residents of Lhasa (3658 m). Respir Physiol 1996;103:75-82.

90 Chao J, Viets Z, Donham P, Wood JG, Gonzalez NC: Dexamethasone blocks the systemic inflammation of alveolar hypoxia at several sites in the inflammatory cascade. Am J Physiol Heart Circ Physiol 2012;303:H168-H177.

91 Urner M, Herrmann IK, Booy C, RothZ'Graggen B, Maggiorini M, Beck-Schimmer B: Effect of hypoxia and dexamethasone on inflammation and ion transporter function in pulmonary cells. Clin Exp Immunol 2012; 169:119-128.

92 Vergadi E, Chang MS, Lee C, Liang OD, Liu $\mathrm{X}$, Fernandez-Gonzalez A, Mitsialis SA, Kourembanas S: Early macrophage recruitment and alternative activation are critical for the later development of hypoxia-induced pulmonary hypertension. Circulation 2011; 123:1986-1995

93 Wang H, Tang Y, Zhang YL, Hypoxic pulmonary hypertension (HPH) and iptakalim, a novel ATP-sensitive potassium channel opener targeting smaller arteries in hypertension. Cardiovasc Drug Rev 2005;23:293-316.

94 Zhu R, Bi LQ, Wu SL, Li L, Kong H, Xie WP, Wang H, Meng ZL: Iptakalim attenuates hypoxia-induced pulmonary arterial hypertension in rats by endothelial function protection. Mol Med Rep 2015;12:2945-2952.

95 Krystel-Whittemore M, Dileepan KN, Wood JG: Mast Cell: A multi-functional master cell. Front Immunol 2015;6:620.

96 Steiner DR, Gonzalez NC, Wood JG: Mast cells mediate the microvascular inflammatory response to systemic hypoxia. J Appl Physiol 2003;94:325-334

97 Gonzalez NC, Allen J, Schmidt EJ, Casillan AJ, Orth T, Wood JG: Role of the renin-angiotensin system in the systemic microvascular inflammation of alveolar hypoxia. Am J Physiol Heart Circ Physiol 2007;292:H2285H2294.

98 Wang Z, Tao J, Zhang Q, Wei M: Effect of oxygen and glucose deprivation on VEGF and its receptors in microvascular endothelial cells co-cultured with mast cells. Cell Biol Int 2015;39:1016-1025.

99 Garcia-Roman J, Ibarra-Sanchez A, Lamas M, Gonzalez Espinosa C: VEGF secretion during hypoxia depends on free radicals-induced Fyn kinase activity in mast cells. Biochem Biophys Res Commun 2010;401:262-267.
100 Mungall IP: Hypoxia and lung mast cells: influence of disodium cromoglycate. Thorax 1976;31:94-100.

101 Banasova A, Maxova H, Hampl V, Vizek M, Povysilova V, Novotna J, Vajnerova O, Hnilickova O, Herget J: Prevention of mast cell degranulation by disodium cromoglycate attenuates the development of hypoxic pulmonary hypertension in rats exposed to chronic hypoxia. Respiration 2008;76:102107.

102 Maxova H, Herget J, Vizek M: Lung mast cells and hypoxic pulmonary hypertension. Physiol Res 2012;61:1-11.

103 Farha S, Sharp J, Asosingh K, Park M, Comhair SA, Tang WH, Thomas J, Farver C, Hsieh F, Loyd JE, Erzurum SC: Mast cell number, phenotype, and function in human pulmonary arterial hypertension. Pulm Circ 2012;2:220-228.

104 Williams A, Heath D, Kay JM, Smith P: Lung mast cells in rats exposed to acute hypoxia, and chronic hypoxia with recovery. Thorax 1977;32:287-295.

105 Maxova H, Bacakova L, Lisa V, Novotna J, Tomasova H, Vizek M, Herget J: Production of proteolytic enzymes in mast cells, fibroblasts, vascular smooth muscle and endothelial cells cultivated under normoxic or hypoxic conditions. Physiol Res 2010;59:711719.

106 Vajner L, Vytasek R, Lachmanova V, Uhlik J, Konradova V, Novotna J, Hampl V, Herget J: Acute and chronic hypoxia as well as 7-day recovery from chronic hypoxia affects the distribution of pulmonary mast cells and their MMP-13 expression in rats. Int J Exp Pathol 2006;87:383-391.

107 Nozik-Grayck E, Stenmark KR: Role of reactive oxygen species in chronic hypoxia-induced pulmonary hypertension and vascular remodeling. Adv Exp Med Biol 2007;618: 101-112.

108 Aggarwal S, Gross CM, Sharma S, Fineman JR, Black SM: Reactive oxygen species in pulmonary vascular remodeling. Compr Physiol 2013;3:1011-1034.

109 Wood JG, Johnson JS, Mattioli LF, Gonzalez NC: Systemic hypoxia promotes leukocyteendothelial adherence via reactive oxidant generation. J Appl Physiol 1999;87:17341740.

110 Wood JG, Johnson JS, Mattioli LF, Gonzalez NC: Systemic hypoxia increases leukocyte emigration and vascular permeability in conscious rats. J Appl Physiol 2000;89:15611568.

111 Zhu YJ, Kradin R, Brandstetter RD, Staton G, Moss J, Hales CA: Hypoxic pulmonary hypertension in the mast cell-deficient mouse. J Appl Physiol Respir Environ Exerc Physiol 1983;54:680-686.

112 Richards F, Smith P, Heath D: The influence of hypoxia on the population density of alveolar macrophages in the lungs of rats. Invest Cell Pathol 1980;3:409-413.
113 Ohwada A, Kira S, Yamashita T: Influence of hypoxia on 5-lipoxygenase pathway in rat alveolar macrophages. Prostaglandins Leukot Essent Fatty Acids 1990;39:69-73.

114 Hempel SL, Monick MM, Hunninghake GW: Effect of hypoxia on release of IL-1 and TNF by human alveolar macrophages. Am J Respir Cell Mol Biol 1996;14:170-176.

115 Vozzelli MA, Mason SN, Whorton MH, Auten RL Jr: Antimacrophage chemokine treatment prevents neutrophil and macrophage influx in hyperoxia-exposed newborn rat lung. Am J Physiol Lung Cell Mol Physiol 2004;286:L488-L493.

116 Nyga A, Hart A, Tetley TD: Importance of the HIF pathway in cobalt nanoparticle-induced cytotoxicity and inflammation in human macrophages. Nanotoxicology 2015;9: 905-917.

117 Kay JM, Waymire JC, Grover RF: Lung mast cell hyperplasia and pulmonary histamineforming capacity in hypoxic rats. Am J Physiol 1974;226:178-184.

118 Hales CA, Kazemi H: Role of histamine in the hypoxic vascular response of the lung. Respir Physiol 1975;24:81-88.

119 Volkel N, Kaukel E, Trautmann J: Accumulation of histamine and cyclic nucleotides in lung tissue during chronic hypobaric hypoxia. Lung 1978; 155:277-286.

120 Porcelli RJ, Ventura DF, Mahoney WA, Bergofsky $\mathrm{EH}$ : Role of histamine in regulating pulmonary vascular tone and reactivity. J Appl Physiol Respir Environ Exerc Physiol 1981;51:1320-1325.

121 Peters SP, Lichtenstein LM, Adkinson NF Jr: Mediator release from human lung under conditions of reduced oxygen tension. J Pharmacol Exp Ther 1986;238:8-13.

122 Paterson NA: Influence of hypoxia on histamine and leukotriene release from dispersed porcine lung cells. J Appl Physiol 1986;61: 1790-1795.

123 Gordon JB, Clément de Cléty S, Chu K: Developmental changes in vascular responses to histamine in normoxic and hypoxic lamb lungs. J Appl Physiol 1991;70:323-330.

124 MacDonald SM, Lichtenstein LM: Histamine-releasing factors and heterogeneity of IgE. Springer Semin Immunopathol 1990; 12:415-428

125 Diaz P, Jones DG, Kay AB: Histaminecoated particles generate superoxide $(\mathrm{O}-2)$ and chemiluminescence in alveolar macrophages. Nature 1979;278:454-456.

126 Nomura H, Sato E, Koyama S, Haniuda M, Kubo K, Nagai S, Izumi T: Histamine stimulates alveolar macrophages to release neutrophil and monocyte chemotactic activity. J Lab Clin Med 2001;138:226-235.

127 Triggiani M, Gentile M, Secondo A, Granata F, Oriente A, Taglialatela M, Annunziato L, Marone G: Histamine induces exocytosis and IL-6 production from human lung macrophages through interaction with $\mathrm{H} 1 \mathrm{re}-$ ceptors. J Immunol 2001;166:4083-4091. 